\title{
Change in prostaglandin E synthases (PGESs) in microsomal PGES-1 knockout mice in a preterm delivery model
}

\author{
Ken Kubota ${ }^{1,2}$, Toshiro Kubota ${ }^{2}$, Daisuke Kamei ${ }^{3}$, \\ Makoto Murakami ${ }^{3}$, Ichiro Kudo ${ }^{3}$, Takeshi Aso $^{2}$ \\ and Ikuo Morita ${ }^{1}$ \\ ${ }^{1}$ Department of Cellular Physiological Chemistry, Tokyo Medical and Dental University, 1-5-45 Yushima, Bunkyo-ku, Tokyo 113-8519, Japan \\ ${ }^{2}$ Department of Comprehensive Reproductive Medicine, Tokyo Medical and Dental University, 1-5-45 Yushima, Bunkyo-ku, Tokyo 113-8519, Japan \\ ${ }^{3}$ Department of Health Chemistry, School of Pharmaceutical Sciences, Showa University, 1-5-8 Hatanodai, Shinagawa-ku, Tokyo 142-8555, Japan \\ (Requests for offprints should be addressed to I Morita; Email: morita.cell@tmd.ac.jp)
}

\begin{abstract}
Most preterm deliveries are associated with infection and inflammation. Prostaglandin $\mathrm{E}_{2}\left(\mathrm{PGE}_{2}\right)$ is one of the most important mediators in the processes of inflammation, and is converted from $\mathrm{PGH}_{2}$ by various kinds of PGE synthases (PGESs). Among PGESs, microsomal PGES-1 (mPGES-1) is known to be the most important subtype in the processes of inflammation. To evaluate the role of PGESs in preterm delivery, we used mPGES-1 knockout mice in a lipopolysaccharide (LPS)-induced preterm labor model. Unexpectedly, the duration of labor after LPS treatment was not statistically different between C57BL6 wild-type mice and mPGES-1 knockout mice.
\end{abstract}

In wild-type mice, mPGES-1 mRNA and protein expression increased in the myometrium and fetal membrane after LPS treatment. In contrast, the expression of mPGES-2 or cytosolic PGES was not changed by LPS treatment. On mPGES-1 knockout mice, mPGES-2 increased by LPS treatment in myometrium. The present data indicate that mPGES-1 may be involved in LPSinduced preterm labor, but inhibition of mPGES-1 alone may not prevent preterm delivery, because mPGES-2 might compensate for the role of mPGES-1.

Journal of Endocrinology (2005) 187, 339-345

\section{Introduction}

Preterm delivery is the leading cause of perinatal mortality and morbidity. Most preterm deliveries are associated with intrauterine infection. Prostaglandin $\mathrm{E}_{2}\left(\mathrm{PGE}_{2}\right)$ is thought to be a very important autacoid which regulates fever, swelling, pain, tumorigenesis, gastrointestinal protection, osteogenesis and wound healing (Funk 2001, Harris et al. 2002, Murakami \& Kudo 2004). PGE $_{2}$ production from arachidonic acid, which is released by phospholipase $A_{2}$ from membrane phospholipids, is controlled by two ratelimiting steps (Funk 2001, Harris et al. 2002, Murakami \& Kudo 2004). The first step is catalyzed by cyclooxygenase (COX), which converts arachidonic acid to the intermediate prostanoid $\mathrm{PGH}_{2}$. Two isoforms of the COX enzymes have been identified: COX-1, which is a constitutive enzyme; and COX-2, which is induced by various stimuli, including cytokines, growth factors, tumor promoters and lipopolysaccharide (LPS). The second step is the terminal conversion reaction of $\mathrm{PGH}_{2}$ to $\mathrm{PGE}_{2}$, which is catalyzed by PGE synthase (PGES) (Jakobbsson et al. 1999, Murakami et al. 2000, 2003). Nowadays, three isozymes of PGE synthase have been identified: microsomal PGE synthase-1 (mPGES-1) (Jakobbsson et al. 1999); microsomal PGE synthase-2 (mPGES-2) (Watanabe et al. 1999, Tanikawa et al. 2002); and cytosolic PGE synthase (cPGES) (Tanioka et al. 2000).

Among these three enzymes, mPGES-1, which was originally designated as membrane-bound glutathione S-transferase1-like 1 (MGST1-L1), is the most important isozyme in infectious response (Jakobbsson et al. 1999). This isozyme is thought to be coordinately induced with COX-2 on the perinuclear membrane and is functionally coupled with COX-2 in marked preference to COX-1 (Murakami et al. 2000). mPGES-1 expression is induced by pro-inflammatory stimuli in various tissues and cells, and is down-regulated by dexamethasone, accompanied by change in COX-2 expression and $\mathrm{PGE}_{2}$ production (Murakami et al. 2000). COX-2 and mPGES-1, therefore, are thought to be essential components for $\mathrm{PGE}_{2}$ biosynthesis under pathological conditions. mPGES-2 was originally extracted from bovine heart (Watanabe et al. 1999, Tanikawa et al. 2002). This isozyme was synthesized as a Golgi membrane-associated protein and by spontaneous cleavage of the N-terminal hydrophobic domain, and led to the formation of a truncated protein that was 
Table 1 Primers used in the experiments

\begin{tabular}{|c|c|c|c|c|}
\hline & Forward primer & Reverse primer & Genbank accession number & Base pair \\
\hline COX-1 & 5'-gcatgtggctgtggatgtca-3' & 5'-ggtcttggtgttgaggcaga-3' & ВС005573.1 & 388 \\
\hline $\mathrm{COX}-2$ & 5'-acactctatcactggcaccc-3' & 5'-gaagggacaccccttcacat-3' & NM011198.1 & 585 \\
\hline mPGES-2 & $5^{\prime}$-ccaggacggaggagatgaagtg-3' & $5^{\prime}$-ccaaggctggatgtgtgagtgt-3' & BC004846 & 307 \\
\hline cPGES & $5^{\prime}$-atgcagcctgcttctgca-3' & $5^{\prime}$-ttactccagatctggcat- $3^{\prime}$ & L24804 & 483 \\
\hline$\beta$-actin & $5^{\prime}$-attgtgatggactccggtgacgg-3' & $5^{\prime}$-atcttgatcttcatggtgctagg- $3^{\prime}$ & M12481.1 & 536 \\
\hline
\end{tabular}

distributed in the cytosol with a trend to be enriched in the perinuclear region. $\mathrm{mPGES}-2$ promoted $\mathrm{PGE}_{2}$ production via both COX-1 and COX-2 in the immediate and delayed responses with modest preferences (Murakami et al. 2003). cPGES, which was identified as the heat shock protein 90 (HSP90)-associated protein $\mathrm{p} 23$, is thought to be constitutive and to be linked with COX-1 (Tanioka et al. 2000).

In previous studies, it has been reported that female mPGES-1 knockout mice showed no functional defects in reproductive behavior (Uematsu et al. 2002, Trebino et al. 2003). Here, to understand the role of mPGES-1 in preterm delivery due to the infectious response, we investigated whether or not the duration of labor in the LPS-induced preterm delivery model was affected, and also investigated the changes in expression patterns of various PGESs in preterm delivery.

\section{Materials and Methods}

\section{Animals}

C57BL6 mice (wild-type) were obtained from the Sankyo laboratory. The mPGES-1 knockout mice (C57BL6 $\times$ $129 / \mathrm{SvJ}$ background) were as described previously (Uematsu et al. 2002, Kamei et al. 2004). As previously demonstrated, normal mPGES-1 protein was not produced in these knockout animals (Uematsu et al. 2002). Female mice (10-12 weeks old) were mated overnight to obtain pregnant females. Mating was confirmed by the presence of seminal plug or sperm. Seminal plug day was designated as day 0 and represented the beginning of the gestational period. The duration of pregnancy in both wild-type and mPGES-1 knockout mice was 19 days. There were no differences between each group statistically. All experiments were performed with the approval of the Tokyo Medical and Dental University.

\section{Agents}

LPS and Escherichia coli 055:B were purchased from Sigma. Rabbit anti-mPGES-1 polyclonal antibodies and rabbit anti-cPGES antibodies were purchased from Cayman
Chemicals (Ann Arbor, MI, USA). Rabbit anti-mPGES-2 antibodies were produced in our laboratory. The antibody against mPGES-2 was not cross-reacted with mPGES-1 and cPGES. Mouse anti- $\alpha$ tublin polyclonal antibodies were purchased from Sigma. Anti-rabbit IgG antibodies and anti-mouse IgG antibodies, and enzyme immunoassay kits for $\mathrm{PGE}_{2}$ were purchased from Amersham.

\section{Preterm delivery model with LPS treatment}

LPS or saline were injected i.p. at $5 \mathrm{mg} / \mathrm{kg}(150-170 \mu \mathrm{g}$ per mouse) in the mice on day 15 . The duration of labor after LPS administration was counted every $0 \cdot 5 \mathrm{~h}$.

\section{RNA extraction}

Total RNA was extracted from tissue specimens after homogenization in Trizol reagent (Invitrogen) according to the manufacturer's instruction. The quantity and quality of the RNA was verified by spectrophotometry.

\section{Reverse transcription (RT)-PCR}

One microgram of total RNA was used as a template for cDNA synthesis. The cDNA was prepared using random primers and River Tra Ace (TOYOBO, Osaka, Japan). PCR primers were designed and synthesized on the basis of reported mouse cDNA sequences for COX-1, COX-2, mPGES-1, mPGES-2, cPGES and $\beta$-actin (Table 1). Each PCR reaction was performed in a $25 \mu \mathrm{l}$ mixture containing Ex Taq, dNTP (TAKARA, Tokyo, Japan) and primers. Cycling conditions were as follows: denaturation for $40 \mathrm{~s}$ at $94{ }^{\circ} \mathrm{C}$, annealing for $30 \mathrm{~s}$ at $62{ }^{\circ} \mathrm{C}$ and extension for $45 \mathrm{~s}$ at $72{ }^{\circ} \mathrm{C}$ for COX-1 (28 cycles), COX-2 (32 cycles) and $\beta$-actin (22 cycles); denaturation for $40 \mathrm{~s}$ at $94{ }^{\circ} \mathrm{C}$, annealing for $30 \mathrm{~s}$ at $58{ }^{\circ} \mathrm{C}$, extension for $45 \mathrm{~s}$ at $72{ }^{\circ} \mathrm{C}$ for mPGES-1 (30 cycles) and mPGES-2 (30 cycles); and denaturation for $40 \mathrm{~s}$ at $94{ }^{\circ} \mathrm{C}$, annealing for $30 \mathrm{~s}$ at $50{ }^{\circ} \mathrm{C}$, extension for $45 \mathrm{~s}$ at $72{ }^{\circ} \mathrm{C}$ for cPGES (25 cycles).

After amplification, the PCR products were resolved by $1 \cdot 2 \%$ agarose gel electrophoresis and visualized by ethidium bromide (Sigma). 
Table 2 Primers and probe pairs used in the experiments

Forward primer

mPGES-1 5'-accgcaacgacatggag-3'

mPGES-2 5'-gcgacactcacacatccag-3'

$\beta$-actin $\quad 5^{\prime}$-cctgtatgcctctggtcgta-3'
Reverse primer

$5^{\prime}$-ggttcagcttgccaggta-3'

$5^{\prime}$-gtggaccagagacaaaatgact-

$5^{\prime}$-ccatctcctgctcgaagtct-3'
Probe 1

5'-cgaagccgaggaagaggaaaggatagatt-3'

$5^{\prime}$-gatggagcgggccattgaagaagc- $3^{\prime}$

$5^{\prime}$-ctgagagggaaatcgtgcgtgacatc- $3^{\prime}$
Probe 2

5'-agggttgggtcccaggaatgagtac- $3^{\prime}$ $5^{\prime}$-ccctcggtgcatcatgtcaaccc-3'

$5^{\prime}$-cgtggctacagcttcaccaccaca-3'

\section{Real-time quantitative PCR}

Quantification of relative mRNA abundance for mPGES-1 and mPGES-2 was performed by real-time PCR amplification in a Light Cycler (Roche) instrument using hybridization probe methods. Each hybridization probe was designed and synthesized on the basis of mouse sequences reported by Japanese gene research laboratories. The primers and probe pairs are shown in Table 2. A $20 \mu \mathrm{l}$ PCR reaction was used and included quantitative PCR master mix (Qiagen), primers, probes and reversed transcribed cDNA. For quantification, standard curves were described using serial dilutions of the appropriate plasmid. Each PCR product was confirmed by size determination using agarose gel electrophoresis. Data obtained from the Light Cycler were normalized against $\beta$-actin.

\section{Protein preparation}

Tissues was harvested and frozen in liquid nitrogen and kept at $-80{ }^{\circ} \mathrm{C}$ until processed. Tissues were homogenized in $0.25 \%$ sucrose, $5 \mathrm{mM}$ EDTA, $3 \%$ Triton $\times 100$ and protease inhibitor cocktail (Sigma). The homogenates were centrifuged at $10000 \mathrm{~g}$ for $10 \mathrm{~min}$. A portion of supernatants was used to prepare the microsomal fraction by centrifugation at $56000 \mathrm{~g}$ for $60 \mathrm{~min}$. The supernatants were used for cytosolic fractions. The pellets were solubilized in $250 \mathrm{mM}$ sucrose, $5 \mathrm{mM}$ EDTA, 3\% Triton $\times 100$ and protease inhibitor cocktail. Protein context was measured using a protein assay kit (BioRad) using bovine albumin as standard. Fractions were kept at $-20{ }^{\circ} \mathrm{C}$ until further analysis.

\section{SDS-PAGE and immunoblotting}

Twenty microgram of microsomal protein extracts were subjected to electrophoresis on 15\% SDS-PAGE gel and transferred to PVDF membranes. Membranes were blocked in TBS and $0 \cdot 1 \%$ Tween 20 containing 5\% dry milk (TBS-T) and then incubated with mPGES-1 $(\times 1000)$, mPGES-2 $(\times 5000)$, cPGES $(\times 1000)$ and $\alpha$-tublin $(\times 5000)$.

After incubation with primary antibody, the membrane was washed in TBS- $T$ four times for 15 min each and then exposed to horseradish peroxidase-conjugated anti-mouse or anti-rabbit IgG secondary antibody $(\times 5000)$ at $4{ }^{\circ} \mathrm{C}$ for $2 \mathrm{~h}$. Detections were performed using ECL plus western blotting detection reagents (Amersham). Signal strength was digitized and quantified using RAS1000 plus (Fuji Film, Tokyo, Japan).

\section{Statistics}

Data are expressed as means \pm S.D. and were compared using the Mann-Whitney $U$-test. A $P$ value of less than $0 \cdot 05$ was considered to be statistically significant.

\section{Results}

Duration of labor after LPS treatment in mPGES-1 knockout mice

The duration of labor in LPS-treated wild-type mice was $10.95 \pm 0.59 \mathrm{~h}$ (mean \pm S.D.), and that in LPStreated mPGES-1 knockout mice was $11.60 \pm 0.93 \mathrm{~h}$ (mean \pm S.D.). There was no significant difference between mPGES-1 knockout mice and wild-type mice (Fig. 1).

Gene expression of mPGES-1, mPGES-2 and CPGES in LPS-treated pregnant mice

It was observed by RT-PCR that in the myometrium, placenta and fetal membrane in the wildtype mice, COX-2 mRNA production increased at $6 \mathrm{~h}$ after LPS treatment, but COX-1 and cPGES-1 mRNA were not influenced by LPS treatment. mPGES-1 mRNA expression was elevated in the myometrium and placenta, while mPGES-2 mRNA expression in these tissues was not affected by LPS treatment (Fig. 2a).

To confirm the gene expression of mPGES-1 and mPGES-2 in each tissue, we conducted quantitative real-time PCR. mPGES-1 mRNA expression in the myometrium and fetal membrane increased at $6 \mathrm{~h}$ after LPS treatment, but that in placenta tended to increase (Fig. 3a). mPGES-2 expression in each tissue, however, did not change in these tissues following LPS treatment (Fig. 3b). 


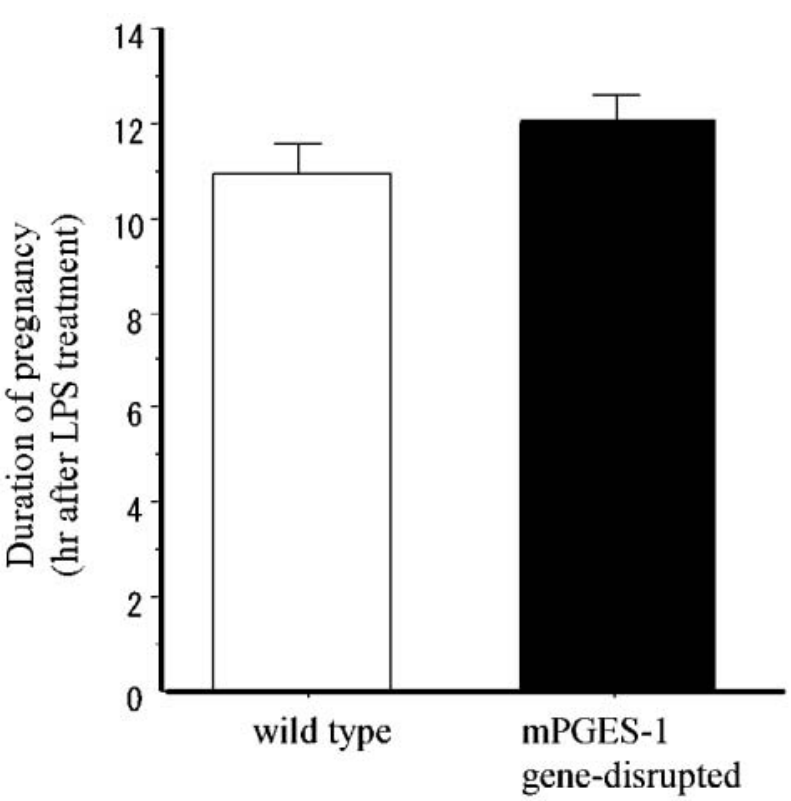

Figure 1 Duration of labor after LPS treatment in wild-type mice and mPGES- 1 knockout mice. LPS or saline were injected i.p. at $5 \mathrm{mg} / \mathrm{kg}$ (150-170 $\mu \mathrm{g}$ per mouse) in mice. The duration of labor after LPS administration was counted every $0.5 \mathrm{~h}$. Values are presented as means \pm S.D. Wild-type mice, $n=11$; mPGES- 1 knockout mice, $n=7$.

Expression of mPGES-1 and mPGES-2 proteins after LPS treatment

mPGES-1 and mPGES-2 protein levels in the myometrium, placenta and fetal membrane were detected by western blotting, and were normalized by $\alpha$-tublin. In wild-type mice, in the myometrium mPGES-1 protein level as well as mRNA expression increased at $6 \mathrm{~h}$ after LPS treatment (Fig. 4a); levels in the placenta tended to increase, but not this was not significant. In contrast, mPGES-2 protein did not increase after LPS treatment in the myometrium, placenta and fetal membrane of wild-type mice (Fig. 4b).

Gene and protein expression of mPGES-2 after LPS treatment in $m P G E S-1$ knockout mice

RT-PCR showed that mRNA expression of COX-2 and mPGES-2 in the myometrium of mPGES-1 knockout mice increased at $6 \mathrm{~h}$ after LPS treatment, but COX-1 and cPGES-1 mRNA were not influenced by LPS treatment (Fig. 2b). The upregulation of $\mathrm{mPGES}-2 \mathrm{mRNA}$ in the myometrium, but not in placenta and fetal membrane, at $6 \mathrm{~h}$ after LPS treatment was confirmed by quantitative real-time PCR (Fig. 5). The difference in expression of mPGES-2 mRNA and proteins in the myometrium between wild-type and mPGES-1 knockout mice was more clearly observed at labor after LPS treatment (Fig. 6). a) Wild-Type

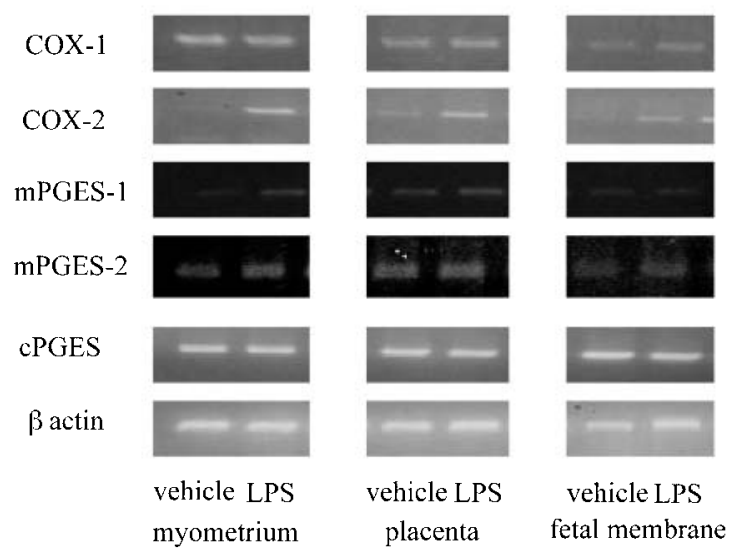

\section{b) mPGES-1 gene-disrupted}

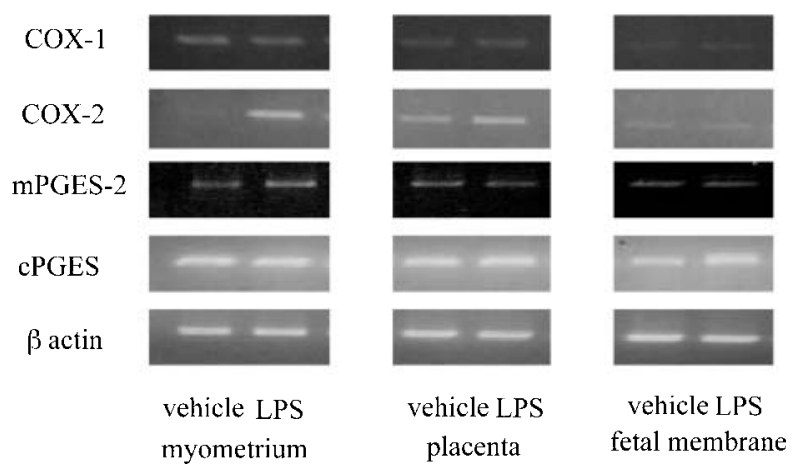

Figure 2 Gene expression of COX-1, COX-2, mPGES-1 and mPGES-2 in the myometrium, placenta and fetal membrane at $6 \mathrm{~h}$ after LPS treatment in (a) wild-type mice and (b) mPGES-1 knockout mice. At $6 \mathrm{~h}$ after LPS treatment, the myometrium, placenta and fetal membrane were isolated from (a) wild-type mice and (b) mPGES-1 knockout mice, and $1 \mu \mathrm{g}$ total RNA in each tissue was used for RT-PCR.

\section{Discussion}

In the majority of cases, preterm birth is associated with microbial invasion of the chorion, amnion, endometrium or placenta, with inflammatory cytokines in the amniotic fluid, or with preterm fetal membranes. Currently, nonsteroidal anti-inflammatory drugs (NSAIDs) such as indomethacin have been shown to be effective in delaying labor in the short-term (48-72 h), suggesting that PGs are involved in preterm birth. Among several PGs, $\mathrm{PGE}_{2}$ is the most important mediator that plays a variety of roles in biological events (Funk 2001, Harris et al. 2002, Murakami et al. 2004). Moreover, Cook et al. (2000) reported that an increase in $\mathrm{PGF}_{2 \alpha}$ was not necessary for preterm labor and that increases in COX-2 at the time of preterm birth might underlie $\mathrm{PGE}_{2}$ change. Among PGE 
(a) mPGES-1

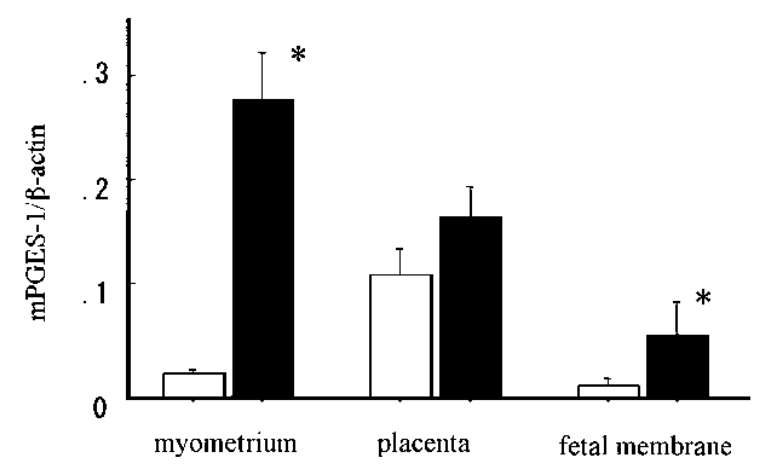

(b) MPGES-2

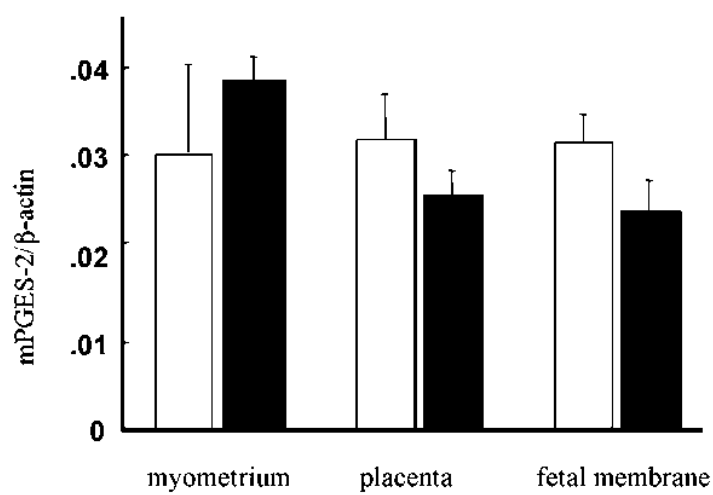

Figure 3 Quantitative analysis of gene expression of (a) mPGES-1 and (b) mPGES-2 in the myometrium, placenta and fetal membrane at $6 \mathrm{~h}$ after LPS treatment in wild-type mice. At $6 \mathrm{~h}$ after LPS treatment, the myometrium, placenta and fetal membrane were isolated from the wild-type mice. Open bars indicate control and filled bars show LPS-treatment. CDNA extracted from the tissues was measured by Light Cycler real-time PCR to assess the level of mPGES-1 and mPGES-2 mRNA. Data obtained from the Light Cycler were normalized against $\beta$-actin. Values are presented as means \pm S.D $(n=5) .{ }^{*} P<0 \cdot 01$.

synthases, mPGES-1 is induced by pro-inflammatory stimuli in various tissues and cells, and is down-regulated by dexamethasone, indicating that COX-2 and mPGES-1 are essential for $\mathrm{PGE}_{2}$ biosynthesis under pathological conditions. These reports led us to the hypothesis that mPGES-1 is involved in preterm labor. Therefore, we investigated whether the duration of labor after LPS treatment was elongated in mPGES-1 knockout mice. However, unexpectedly there was no significant difference in the duration of labor between mPGES-1 knockout mice and wild-type mice. In previous investigations, the normal reproductive systems in mPGES-1 knockout mice also showed no abnormality (Uematsu et al. 2002, Trebino et al. 2003). In contrast, COX-2 knockout mice
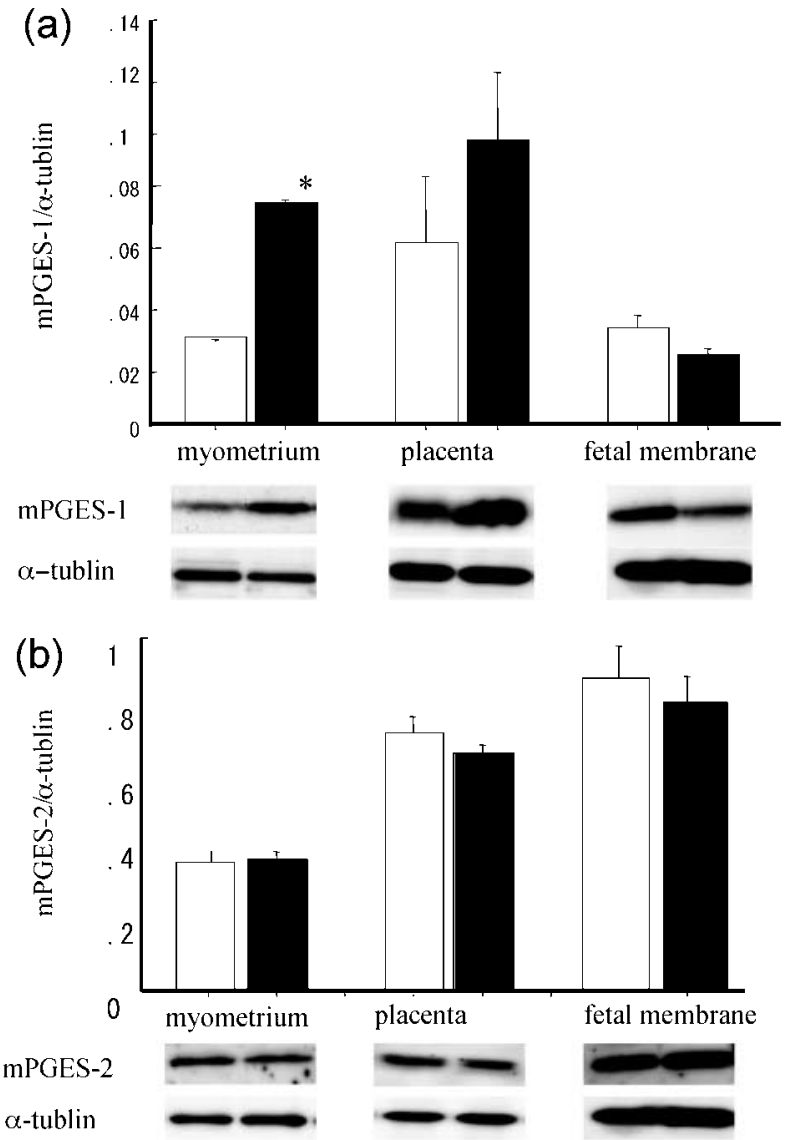

Figure 4 Representative western blot of (a) mPGES-1 and (b) mPGES-2 protein in wild-type mice and quantification by densitometry. Proteins in the microsomal fraction isolated from the myometrium, placenta and fetal membrane in wild-type mice at $6 \mathrm{~h}$ after LPS treatment were subjected to western blotting and the data obtained from densitometry were normalized against $\alpha$-tublin. Open bars indicate control and filled bars show LPS-treatment. The densitometric results in four independent experiments represent the means $\pm S . D{ }^{*} P<0 \cdot 05$.

showed female reproductive abnormalities with defects in ovulation, fertilization, implantation and decidualization (Lim et al. 1997), and $\mathrm{PGE}_{2}$ receptor, EP2 knockout mice showed a defect in ovulation (Kennedy et al. 1999, Tilley et al. 1999).

To examine the contribution of other PGESs in LPSinduced preterm delivery, the changes in PGES expression pattern were observed in wild-type mice. However, only the expression of mPGES-1 increased in the myometrium and fetal membrane after LPS treatment, and the expression of mPGES-2 and cPGES were not changed after LPS treatment. In contrast to the wild-type mice, elevated mPGES-2 mRNA in the myometrium afterLPS treatment was observed in mPGES-1 knockout mice. This indicates that mPGES-2 may compensate functionally for the loss of mPGES-1. This compensation has been 


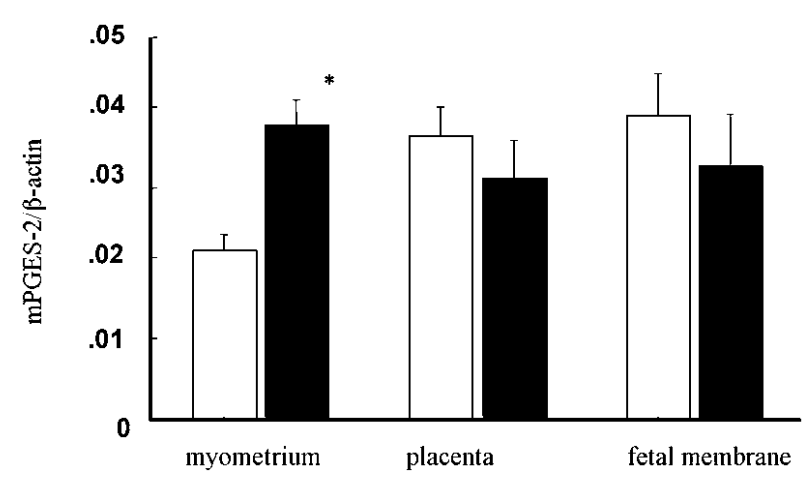

Figure 5 Quantitative analysis of gene expression of mPGES-2 in the myometrium, placenta and fetal membrane at $6 \mathrm{~h}$ after LPS treatment in mPGES-1 knockout mice. At $6 \mathrm{~h}$ after LPS treatment, the myometrium, placenta and fetal membrane were isolated from mPGES-1 knockout mice. Open bars indicate control and filled bars indicate LPS-treatment. cDNA extracted from the tissues was measured by Light Cycler real-time PCR to assess the level of mPGES-2 mRNA. Open bars indicate control and filled bars indicate LPS-treatment. Data obtained from the Light Cycler were normalized against $\beta$-actin. Values are presented as means \pm S.D $(n=6) .{ }^{*} P<0 \cdot 05$.

reported in COX isozymes: interleukin $-1 \beta$ could induce $\mathrm{PGE}_{2}$ synthesis in lung fibroblasts derived from COX-1 knockout mice as well as COX-2 knockout mice (Kirtikara et al. 1998). It has been reported that mPGES-2 expression was not increased appreciably during tissue inflammation or damage (Murakami et al. 2003). As shown in this paper, however, mPGES-2 expression increased following LPS treatment under conditions where mPGES-1 was reduced. The present data demonstrated that mPGES-1 maybe involved in LPS-induced preterm labor, but inhibition of mPGES-1 alone may not prevent preterm delivery, because mPGES-2 might compensate for the role of mPGES-1.

In a recent study, a COX-2-specific inhibitor, as well as indomethacin, induced premature constriction of the fetal ductus arteriosus (Loftin et al. 2002). Therefore, the inhibition of mPGES-1 may be a benefit for preterm delivery, but up to now the specific inhibitors of mPGES1 have not been developed. In this paper, therefore, we used mPGES-1 knockout mice and investigated whether the duration of labor after LPS treatment was elongated. However, mPGES-2 compensated functionally for the loss of mPGES-1, and we failed to show the beneficial effects of mPGES-1 inhibition for preterm labor. Thus, further investigation using mPGES-1 and mPGES-2 double knockout mice is warranted to disclose the role of PGESs in preterm delivery.

\section{Acknowledgement}

The authors thank Dr Shizuo Akira, Osaka University, for providing the mPGES-1 knockout mice. (a)

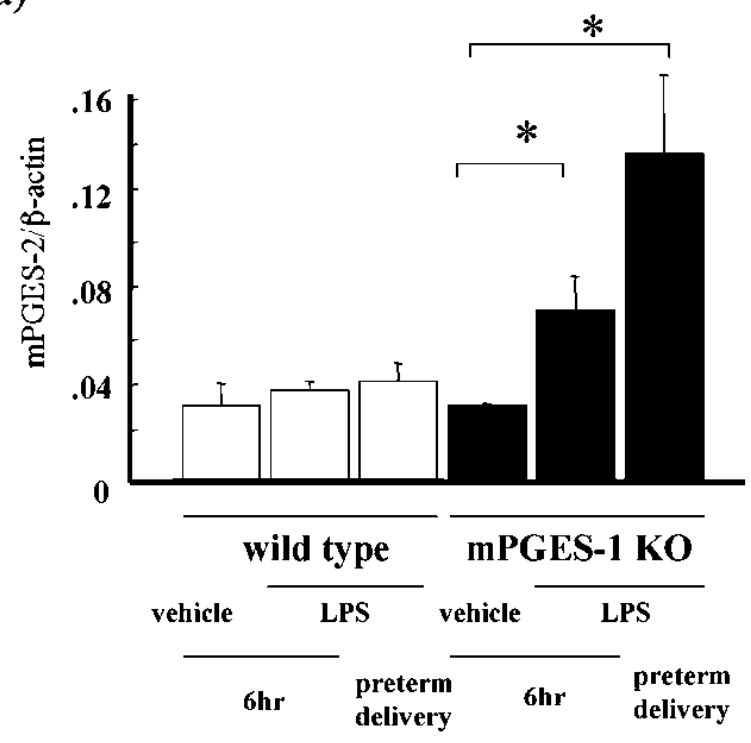

(b)

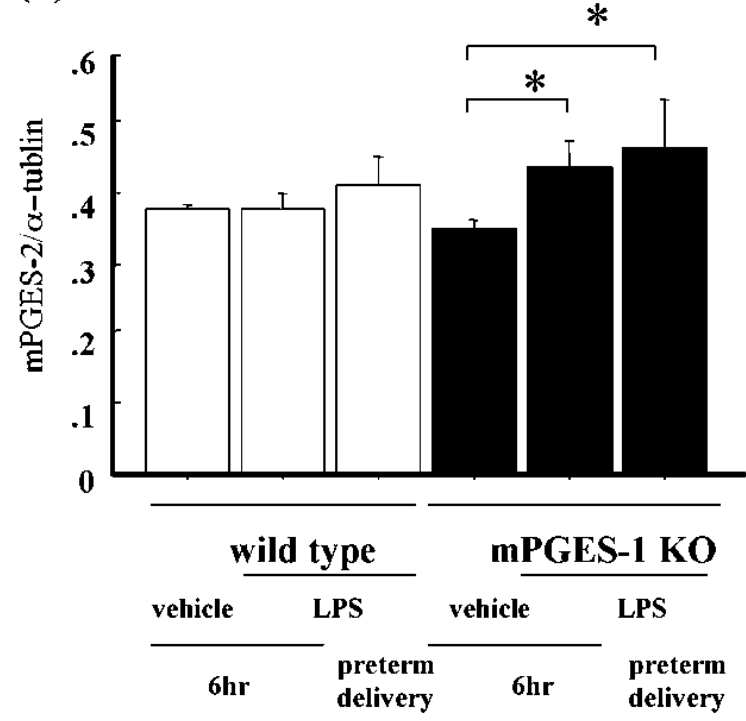

Figure 6 Comparison of (a) mRNA and (b) protein of mPGES-2 expression in the myometrium after LPS treatment between the wild-type mice and mPGES-1 knockout (KO) mice. At $6 \mathrm{~h}$ after LPS treatment and at the time of preterm delivery after LPS treatment, the myometrium was isolated from wild-type mice and mPGES-1 knockout mice. (a) cDNA extracted from the tissues was measured by Light Cycler real-time PCR to assess the level of mPGES-2 mRNA $(n=5)$. (b) Proteins in the microsomal fraction were applied to western blotting and the data obtained from densitometry were normalized against $\alpha$-tublin. The densitometric results of four independent experiments are given as means \pm S.D. ${ }^{*} P<0 \cdot 05$.

\section{Funding}

The authors declare that there is no conflict of interest that would prejudice the impartiality of this scientific work. 


\section{References}

Cook JL, Zaragoza DB, Sung DH \& Olson DM 2000 Expression of myometrial activation and stimulation genes in a mouse model of preterm labor: myometrial activation, stimulation, and preterm labor. Endocrinology 141 1718-1728.

Funk CD 2001 Prostaglandins and leukotriens: advances in eicosanoid biology. Science 294 1871-1875.

Harris SG, Padilla J, Koumas L, Ray D \& Phipps RP 2002 Prostaglandins as modulators of immunity. Trends in Immunology 23 144-150.

Jakobbsson PJ, Thoren S, Morgenstern R \& Samuelsson B 1999 Identification of human prostaglandin synthase: a microsomal, glutathione-dependent, inducible enzyme, constituting a potential novel drug target. PNAS 96 7220-7225.

Kamei D, Yamakawa K, Takegoshi Y, Mikami-Nakanishi M, Nakatani Y, Oh-Ishi S, Yasui H, Azuma Y, Hirasawa N, Ohuchi K, Kawaguchi H, Ichikawa Y, Ishii T, Uematsu S, Akira S, Murakami M \& Kudo I 2004 Reduced pain hypersensitivity and inflammation in mice lacking microsomal prostaglandin e synthase-1. Journal of Biological Chemistry 279 33684-33695.

Kennedy CR, Zhang Y, Brandon S, Guan Y, Coffee K, Funk CD, Magnuson MA, Oates JA, Breyer MD \& Breyer RM 1999 Salt-sensitive hypertension and reduced fertility in mice lacking the prostaglandin EP2 receptor. Nature Medicine 5 217-220.

Kirtikara K, Morham SG, Raghow R, Laulederkiud SJF, Kanekura T, Goorha S \& Ballou LR 1998 Compensatory prostaglandin $\mathrm{E}_{2}$ biosynthesis in cyclooxygenase 1 or 2 null cells. Journal of Experimental Medicine 187 517-523.

Lim H, Paria BC, Das SK, Dinchuk JE, Langenbach R, Trzaskos JM \& Dey SK 1997 Multiple female reproductive failures in cyclooxygenase2-deficient mice. Cell 91 197-208.

Loftin CD, Trivedi DB \& Langenbach R 2002 Cyclooxygenase-1selective inhibition prolongs gestation in mice without adverse effects on the ductus arteriosus. Journal of Clinical Investigation 110 $549-557$.

Murakami M \& Kudo I 2004 Recent advances in molecular biology and physiology of the prostaglandin $\mathrm{E}_{2}$-biosynthetic pathway. Progress in Lipid Research 43 3-35.

Murakami M, Naraba H, Tanioka T, Semmyo N, Nakatani Y, Kojima F, Keda T, Fueki M, Ueno A, Oh-ishi S \& Kudo I 2000 Regulation of prostaglandin $\mathrm{E}_{2}$ biosynthesis by inducible membrane-associated prostaglandin $\mathrm{E}_{2}$ synthase that acts in concert with cyclooxygenase-2. Journal of Biological Chemistry 275 32783-32792.
Murakami M, Nakashima K, Kamei D, Masuda S, Ishikawa Y, Ishi T, Ohmiya Y, Watanabe K \& Kudo I 2003 Cellular prostaglandin $\mathrm{E}_{2}$ production by membrane-bound prostaglandin E synthase-2 via both cyclooxygenase-1 and -2. Journal of Biological Chemistry 278 37937-37947.

Rozen F, Russo C, Banville D \& Zingg HH 1995 Structure, characterization and expression of the rat oxytocin receptor gene. PNAS 92 200-204.

Tanikawa N, Ohmiya Y, Ohkubo H, Hashimoto K, Kangawa K, Kojima M, Ito S \& Watanabe K 2002 Identification and characterization of a novel type of membrane-associated prostaglandin E synthase. Biochemical and Biophysical Research Communications $291884-889$.

Tanioka T, Nakatani Y, Semmyo N, Murakami M \& Kudo I 2000 Molecular identification of cytosolic prostaglandin $E_{2}$ synthase that is functionally coupled with cyclooxygenase- 1 in immediate prostaglandin $\mathrm{E}_{2}$ biosynthesis. Journal of Biological Chemistry 275 32775-32782.

Tilley SL, Audoly LP, Hicks EH, Kim HS, Flannery PJ, Coffman TM \& Koller BH 1999 Reproductive failure and reduced blood pressure in mice lacking the EP2 prostaglandin $\mathrm{E}_{2}$ receptor. Journal of Clinical Investigation 103 1539-1545.

Trebino CE, Stock JL, Gibsons CP, Naiman BM, Watchtmann TS, Umland JP, Pandher K, Lapointe JM, Saha S, Roach ML, Carter D, Thomas NA, Durtshi BA, McNeish JD, Hambor JE, Jakobbson PJ, Carty TJ, Perez JR \& Audoly L 2003 Impaired inflammatory and pain responces in mice lacking an inducible prostaglandin $\mathrm{E}$ synthase. PNAS 100 9044-9049.

Uematsu S, Matsumoto M, Takeda K \& Akira S 2002 Lipopolysaccharide-dependent prostaglandin $\mathrm{E}_{2}$ production is regulated by the glutathione-dependent prostaglandin $\mathrm{E}_{2}$ synthase gene induced by the Toll-like receptor 4/NF-IL6 pathway. Journal of Immunology 168 5811-5816.

Watanabe K, Kurihara K \& Suzuki T 1999 Purification and characterization of membrane-bound prostaglandin E synthase from bovine heart. Biochimica et Biophysica Acta (BBA) Molecular and Cell Biology of Lipids 1439 406-414.

Received 29 August 2005

Accepted 1 September 2005

Made available online as an Accepted Preprint 13 September 2005 